\title{
Recopilación de normas que pueden ser de interés para el experto en relaciones laborales (1-6-95 al 31-12-95)
}

M." CARMEN AGUILAR DEL CASTILLO *

\begin{abstract}
SUMARIO: I. Disposiciones Generales. II. Normas relativas al contrato de trabajo. III. Normas de Seguridad Social. IV. Normas de empleo. V. Normas fiscales y tributarias. VI. Varios
\end{abstract}

\section{Disposiciones Generales}

En este bloque se incluyen aquellas normas de carácter general que pueden interesar a los especialistas en relaciones laborales aprobadas en el período normativo que va desde el 1 de junio al 31 de diciembre de 1995 según su indice cronológico. En ellas figuran normas que no afectan directamente al mundo de las Relaciones Laborales, pero que dado el carácter multidisciplinar de esta diplomatura y la importante repercusión que la actividad de sus universitarios tiene en el mundo laboral, considero necesario incluir aunque sólo sea una mera reseña locativa de las mismas. Dentro de éstas últimas hay que hacer una especial mención a la LO 6/1995 de 29 de junio, ya que se entenderá derogada cuando entre en vigor el nuevo Código Penal aprobado por la LO 10/1995, de 23 de noviembre. Junto a este conjunto de normas se incluyen igualmente las prórrogas de los presupuestos generales del Estado y de la Comunidad Autónoma de Andalucía por la afectación que las mismas pueden tener sobre el Derecho del Trabajo y de la Seguridad Social.

1.- L. Orgánica 6/1995, de 29 de junio, por la que se modifica el Código Penal, delitos contra la Hacienda pública y la seguridad judicial (BOE 30.6).

2.- L. 19/1995 de 4 de julio, sobre modernización de las Explotaciones Agrarias (BOE 5.7)

* Profesora Asociada Universidad de Sevilla. 
3.- L. 25/1995 de 20 de julio, sobre modificación parcial de la Ley General Tributaria (BOE 22.7)

4.- L. Orgánica 10/1995, de 23 de noviembre por la que se aprueba el Código Penal (BOE 24.11) (Entrará en vigor a los seis meses de su publicación).

5.- L. 31/1995 de 8 de noviembre sobre Prevención de Riesgos Laborales (BOE 11.11) (Entrará en vigor a los tres meses de su publicación).

6. - L. 35/1995 de 11 de noviembre de ayudas y asistencia a las víctimas de delitos violentos y contra la libertad sexual (BOE 12.12)

7.- L. 39/1995 de 19 de diciembre sobre organización del centro de investigaciones sociológicas (20.12).

8.- L. 40/1995 de 19 de diciembre, por la que se modifica la L. 38/1992, de 28 de diciembre de Impuestos Especiales (BOE 10.12).

9.- L. 43/1995, de 27 de diciembre, del Impuesto sobre Sociedades (BOE 28.12).

10.- RD. Ley 12/1995, de 28 de diciembre, sobre medidas urgentes en materia presupuestaria, tributaria y financiera (BOE 30.12).

Comunidad Autónoma de Andalucia

11.-D. 289/1995 de 12 de diciembre, sobre prórroga del Presupuesto de la comunidad autónoma de Andalucía para el ejercicio 1996 (BOJA 28.12).

II. Normas relativas al contrato de trabajo

En este apartado se recogen, como su propia denominación establece, aquellas normas que inciden en el conjunto de derechos y obligaciones que van a derivarse de los contratos de trabajo de los trabajadores, materia encuadrable junto al bloque destinado a la seguridad social de una forma directa dentro de los conocimientos más importantes del experto en relaciones laborales.

Del conjunto de estas normas hay que hacer una especial mención por su indudable importancia y trascendencia al Real Decreto sobre Jornadas Especiales, con el que se intenta dar respuesta a todas aquellas particularidades de las distintas actividades profesionales, difícilmente encuadrables en la jornada laboral que con carácter general regula el ET. Junto' a ella hay que destacar la regulación de las Fiestas Laborales, tanto nacionales como a nivel de Comunidad Autónoma y por la importancia que tiene para el trabajador, la fijación del salario mínimo interprofesional para el año 1996. 
- RD 737/1995, de 5 de mayo por el que se modifica el RD 766/1992 de 26 de junio sobre entrada y permanencia en España de nacionales de Estados miembros de las Comunidades Europeas (BOE 5.6).

- RD 797/1995, de 19 de mayo, establece directrices sobre los certificados de profesionalidad y los correspondientes contenidos mínimos de FP Ocupacional (BOE 10.6)

- OM 7 de julio de 1995, da cumplimiento a diversos aspectos del Reglamento de Seguridad Privada, sobre personal (BOE 7.7).

- Resolución 1 de agosto de 1995, de la Subsecretaría por lo que se dispone la publicación de la Resolución de 19.7.1995 de los Directores Generales de Policía, de asuntos consulares, procesos electorales, extranjería y Asilo y de migración (BOE 11.8).

- RD`1561/1995, de 21 de setiembre sobre Jornadas especiales de trabajo (BOE 26.9).

- Resolucion, 29 de noviembre de 1995, Fiestas Laborales para 1996 (BOE 9.12).

- RD 1856/1995, de 17 de noviembre, sobre deportistas de alto nivel (BOE 14.12).

- RD 2199/1995, de 28 de diciembre, por el que se fija el salario mínimo interprofesional para 1996 (BOE 29.12).

Comunidad Autónoma de Andalucía

- D.214/1995 de 19 de setiembre, de adecuación de la relación de puestos de trabajo de la Junta de Andalucía (BOJA 30.9).

- D.227/1995 de 26 de setiembre, por el que se determina el Calendario de Fiestas Laborales de la Comunidad Autónoma de Andalucía para 1996 (BOJA 21.10).

\section{Normas relativas a la Seguridad Social}

La Seguridad Social configura un importante bloque en la normativa necesaria de conocimiento para un esperto en relaciones laborales, teniendo en cuanta las distintas vicisitudes por las que puede atravesar un trabajador y un empresario en su exacto cumplimiento con sus obligaciones y derechos laborales relativos a esta materia.

- RD 1299/1995 de 21 de julio, desarrolla la disposición adicional 32 de la $L$ 42/1994 de 30 de diciembre sobre impagados, retrocesiones y reintegros de pagos indebidos de prestaciones del sistema de la Seguridad Social (BOE 9.9). 
- RD 1300/1995 de 21 de julio, desarrolla en materia de incapacidades laborales del sistema de la Seguridad Social, la L 42/1994 de 30 de diciembre, de medidas fiscales, administrativas y de orden social (BOE 19.8).

- OM de 2 de agosto 1995 sobre composición de las comisiones de control y seguimiento en la gestión desarrollada por las Mutuas de Accidentes de Trabajo y Enfermedades Profesionales de la Seguridad Social, asi como el Reglamento de régimen y funcionamiento (BOE 12.8).

- RD 1391/1995 de 4 de agosto por el que se aprueba el Reglamento General de la Gestión Financiera de la Seguridad Social (BOE 8.8).

- Resolución 20 de setiembre de 1995, Ejercicio función interventora de la Seguridad Social y se establece la realización de un control financiero posterior (BOE 28.9).

- Resolución 20 de setiembre de 1995, Constituye el Equipo de Valoración de Incapacidades en determinadas Direcciones Provinciales del INSS (BOE 29.9).

- RD 1637/1995, de 6 de octubre, Reglamento general de Recaudación de los Recursos del Sistema de la Seguridad Social (BOE 24.10).

- Resolución 25 de octubre de 1995 sobre modelos de Documentos de Cotización vigentes para la liquidación e ingreso de cuotas de la Seguridad Social (BOE 17.11).

- OM 14 de noviembre de 1995, establece límites máximos de los centros administrativos de gestión correspondientes a las Entidades Gestoras de la Seguridad Social (BOE 18.11).

- RD 1859/1995 de 17 de noviembre, sobre forma y plazos de solicitud de la jubilación de funcionarios docentes universitarios (BOE 13.12).

- Resolución de 14 de noviembre de 1995, de la Secretaría General para la Seguridad social, mediante la que se dictan normas de aplicación y desarrollo de la Orden de 2 de Agosto de 1995 sobre las Comisiones de control y seguimiento de las Mutuas de Accidentes de Trabajo y Enfermedades Profesionales de la Seguridad Social (BOE 21.11).

- 0.21 de noviembre de 1995 por el que se regulan las operaciones de cierre del ejercicio de 1995 y se determina la documentación contable que ha de rendirse por los agentes del sistema de la Seguridad Social (BOE 4.12).

- Resolución de 1 de diciembre de 1995 de la Secretaría General para la Seguridad Social, por la que se determina el ámbito territorial de las Unidades de Recaudación Ejecutiva en las Direcciones Provinciales de la Tesorería General de la Seguridad Social (BOE 15.12). 
- RD 1993/1995 de 7 de diciembre Reglamento sobre Colaboración de las Mutuas de Accidentes de Trabajo y Enfermedades Profesionales de la Seguridad Social (BOE 12.12).

Muface: OM 1 de diciembre de 1995 por la que se establecen las normas para el ingreso y control de las cotizaciones de los mutualistas a la Mutualidad General de Funcionarios Civiles del Estado (BOE 11.12).

\section{Normas relativas al empleo}

Bajo este epígrafe se recogen de forma sistemática normas relacionadas con el Instituto Nacional de Empleo u otros organismos tanto públicos como privados, que hacen referencia al fomento de la formación ocupacional, a las ayudas y subvenciones a trabajadores y a futuros empresarios para fomentar el autoempleo y la contratación, así como normas que dan entrada a distintos sectores para participar en la determinación de programas en materia de empleo de actuación conjunta, o aquéllas otras que desarrollan la normativa sobre las agencias de colocación sin fines lucrativos.

- Resolución 7 de julio de 1995 del Instituto Nacional de Empleo, de aplicación y desarrollo de la orden del Ministerio de Trabajo y Seguridad Social de 3 de agosto de 1994, por la que se regulan los programas de Escuelas Taller y Casas de oficios, las unidades de promoción y desarrollo y los Centros de Iniciativa Empresarial y se establecen las bases reguladoras de la concesión de subvenciones públicas a dichos programas (BOE 28.7).

- Resolución 4 de julio de 1995 de la Dirección General del Instituto Nacional de Empleo, por la que se convoca la participación de entidades colaboradoras de dicho Instituto en la realización de acciones de comprobación de la profesionalidad (BOE 9.9).

- OM 1 de setiembre de 1995 por la que se desarrollan los procedimientos de reintegro de cantidades indebidamente percibidas en concepto de subvenciones o ayudas públicas del Instituto Nacional de Empleo (BOE 4.10).

- OM 20 de setiembre de 1995 Modifica la OM de 13 de 4 de 1995 por la que se desarrolla el RD 631/1993, regulador del Plan Nacional de Formación e Inserción Profeşional (BOE 14.10).

- Resolución 29 de setiembre de 1995 del Instituto Nacional de Empleo por la que se determina la composición de la Mesa Central de Contratación del Instituto Nacional de Empleo (BOE 26.10). 
- Resolución 22 de setiembre de 1995 del Instituto Nacional de Empleo por la que se convoca la participación de entidades y centros de colaboradores de dicho instituto en la programación anual de cursos del Plan Nacional de Formación e Inserción Profesional correspondiente al año 1996 (BOE 17.10).

- OM 10 de octubre de 1995 por la que se regulan en desarrollo el Título II del RD 735/1995 de 5 de mayo sobre agencias de colocación sin fines lucrativos y los Servicios Integrados para el Empleo, los Planes de Servicios Integrados para el Empleo y los convenios con las entidades asociadas de los Servicios Integrados para el Empleo (BOE 18.10).

- Orden de 3 de noviembre de 1995, por la que se regula la concesión de ayudas a la formación profesional previstas en el Plan Marco de Modernización del Comercio Interior (BOE 13.11).

- Resolución 5 de diciembre de 1995, del Instituto Nacional de Empleo, por la que se especifican las necesidades del INEM en relación con las acciones contempladas en las letras c), d), e), f), i), de la letra B) del artículo 5 de la Orden de 10 de octubre de 1995, por la que se regulan en desarrollo del título II del Real Decreto 735/1995 de 5 de mayo, sobre agencias de colocación sin fines lucrativos y los servicios integrados para el empleo, los planes de servicios integrados y los convenios con las entidades asociadas a los servicios integrados para el empleo (BOE 20.12).

\section{Comunidad Autónoma de Andalucía}

- D.140/1995 de 23 de mayo, por el que se establecen medidas para paliar los efectos producidos por la sequía (BOJA 30.6).

- D.151/1995, de 13 de junio, por el que se establecen las ayudas para creación de empresas por jóvenes andaluces Programa Empresa Joven (BOJA 13.7).

- D. 226/1995, de 26 de setiembre, por el que se aprueban medidas de ejecución del Plan de Desarrollo Rural de Andalucía (BOJA 28.10).

\section{Normas fiscales y tributarias}

- RD 1165/1995, de 7 de julio, Reglamento de Impuestos Especiales (BOE 28.7).

- RD 2025/1995, de 22 de Diciembre, por el que se modifica el artículo 22 del Reglamento del Impuesto sobre la Renta de las Personas Físicas y se adoptan medidas para dar cumplimiento a lo dispuesto 
por la disposición adicional vigésima sexta de la Ley 42/1994 de 30 de diciembre, de medidas fiscales, administrativas y de orden social (BOE 27.12).

- O. de 22 de diciembre de 1995 por la que se regula el pago de las devoluciones del Impuesto sobre el Valor Añadido a no residentes (BOE 27.12).

- O. de 26 de diciembre de 1995 por la que se aprueban modelos de declaración del Impuesto sobre Actividades Económicas y se establece el modelo de soporte utilizable para el intecambio de información entre la Agencia Estatal de Administración Tributaria y las Entidades que ejercen por delegación la gestión censal del impuesto (BOE 28.12).

\section{Varios}

Como su propia denominación indica son materias difícilmente encuadrables dentro de uno de los epígrafes citados, recogiéndose aquellas normas cuyo conocimiento puede ser de interés para un Diplomado universitario en Relaciones Laborales.

- $\operatorname{RD} 1695 / 1994$, de 20 de octubre establece régimen de ayudas destinadas a fomentar el cese anticipado en la actividad agraria (BOE 4.11).

- Resolución de 22 de diciembre de 1995, de la Secretaría de Estado para la Administración Pública, por la que se establece el calendario de días inhábiles en el ámbito de la Administración General del Estado para el año 1996, a efectos de cómputo de plazos.

- Orden 11 de diciembre de 1995 por la que se crea la Agencia Nacional Española para la aplicación del Programa Comunitario «La Juventud con Europa» (BOE 23.12).

- RD 1409/1995, de 4 de agosto, sobre ampliación de medios adscritos a las funciones y servicios a la Comunidad Autónoma de Andalucía en materia de Juventud (TIVE) (BOJA 26.9).

\section{Comunidad Autónoma de Andalucía}

- D 128/1995, de 9 de mayo, por el que se crea el Comité organizador del Salón Internacional del Estudiante Andalucía'96 (BOJA 1.7).

- O. de 20 de julio de 1995, por la que se desarrolla el art. 2 del D 456/94, de 22 de noviembre, sobre calendario de días inhábiles para 1995, a efectos de cómputo de plazos administrativos (BOJA 29.7). 